\title{
O Papel do/a Enfermeiro/a: Visão Humanística dos Cuidados Paliativos em Pacientes Oncológicos
}

\author{
Elenito Bitencorth Santos ${ }^{1}$
}

Resumo: O estudo em questão aborda à práxis do profissional de enfermagem considerando a ética profissional da referida profissão ao se deparar com o sofrimento dos pacientes oncológicos em estágio terminal. Tal abordagem requer humanização dos cuidados, passando de uma prática paliativa para uma perspectiva holística e multidisciplinar voltada para uma abordagem biopsicosocioespiritual no intuito de proporcionar ao paciente um tratamento adequado e com melhoria da qualidade de vida. O cuidado torna-se uma categoria que possibilita a inter e a multidisciplinaridade e é em torno dele que o vínculo que extrapola o profissionalismo pode ser estabelecido através da efetivação de medidas que criem possibilidades de interação entre enfermeiro-paciente (afeto) e a promoção do autocuidado.

Palavras-chave: Enfermeiro. Pacientes Oncológicos. Cuidados Paliativos. Abordagem Biopsicossocioespiritual.

\section{The Role of the Nurse: Humanistic View of Palliative Care in Cancer Patients}

\begin{abstract}
The present study deals with the praxis of the nursing professional, considering the professional ethics of this profession when faced with the suffering of oncological patients in the terminal stage. Such an approach requires the humanization of care, from a palliative practice to a holistic and multidisciplinary perspective aimed at a biopsychosocial and spiritual approach in order to provide the patient with adequate treatment and improvement of the quality of life. Care becomes a category that enables inter and multidisciplinarity and it is around it that the link that goes beyond professionalism can be established through the implementation of measures that create possibilities for interaction between nurse-patient (affection) and the promotion of self-care.
\end{abstract}

Keywords: Nurse. Oncology Patients. Palliative care. Biopsychosoespiritual approach.

\section{Introdução}

Uma certeza que a sociedade contemporânea vivencia cotidianamente e é presente na vida de todo o ser humano é que, 'o mundo mudou'. Consequentemente, essas mudanças contribuíram para que a individualidade emergisse num mundo cada vez mais carente do social,

\footnotetext{
${ }^{1}$ Mestre em Teologia pela Faculdades EST (EST, São Leopoldo/RS, Brasil). Disponível em: 〈http://www.est.edu.br/>. Enfermeiro especialista em Urgência e Emergência e em Hematologia, Hemoterapia e Terapia de Suporte. Pós-graduado em MBA Executivo em Gestão Hospitalar e Cuidados Paliativos. Funcionário Público da UTI Pediátrica de Vitória da Conquista/Ba. Professor da Educação profissional - Secretaria da Educação / Governo do Estado da Bahia.

E-mail: ebs_2011@hotmail.com
} 
um afastamento inevitável, um isolamento que se confunde com solidão, onde as atitudes de viver e modos de relacionamento com os outros e com nós mesmos também mudaram.

Tudo tem sido tão superficial que o profissional enfermeiro deixou o vínculo afetivo para traz, no intuito de se apoiar em meias verdades (desculpas) de que o relacionar-se com o outro representa fraqueza e falta de profissionalismo.

Assim nasce a esperança de dias melhores, tanto para quem cuida quanto para quem é cuidado, pois através deste binômio, na visão dos profissionais de saúde, particularmente no que diz respeito aos profissionais de enfermagem, acredita-se que ações humanizadas possam contribuir para a satisfação pessoal, para o desenvolvimento pessoal e para o fortalecimento de vínculos entre profissional, paciente e demais atores envolvidos no processo saúde-doença.

Desta forma, e com o olhar voltado para estas possibilidades, o estudo percorre brevemente os caminhos que levam à reflexão sobre as práticas do cuidado do enfermeiro, o acolhimento humanizado por meio de uma visão holística, fundamentada em uma sintonia entre escuta, hospitalidade, respeito, solidariedade e cuidado afetuoso como uma ferramenta útil no atendimento.

Este artigo caracteriza-se basicamente como qualitativo quanto aos meios e de fins exploratórios com paradigma positivista, cujo objetivo é analisar os efeitos causados pelas práticas de enfermagem humanizadas, buscando responder de forma prática e qualificada os questionamentos propostos. Nessa perspectiva, o estudo tem por embasamento, a sequência de uma pesquisa desenvolvida sobre os cuidados paliativos de pacientes oncológicos, estabelecendo a necessidade de proceder com momentos de reflexão por parte de toda a equipe de saúde para a tomada de consciência sobre os aspectos facilitadores que foram identificados a respeito da realidade onde a equipe de saúde atua, subsidiando assim, elementos necessários para propor a construção de indicadores de avaliação.

\section{Cuidado e Humanização no Contexto da Enfermagem}

$\mathrm{Na}$ área da enfermagem, assim como em toda a área relacionada com a clínica curativa, é frequente a vivência e escuta sobre situações de sofrimento e dor, onde a própria história da humanidade permite reportar exemplos de resiliência e fé, pois se tem na figura de Jesus Cristo 
o verdadeiro "Sarador Ferido", uma vez que é pelos seus sofrimentos que somos curados (Is. 53.5: OLIVEIRA, 2007).

Nesse sentido, há uma passagem interessante na obra de Oliveira (2007, p.28) Implicações para as relações de Cuidado - e que vem ao encontro do contexto que por ora se discute, pois de acordo com a autora, "o mito do "sarador ferido" é paradigmática para as relações de ajuda, como bem destacou Henry Nouwen, lembrando Quiron, personagem da mitologia grega que, mesmo sendo exímio na arte de curar, sofria de uma ferida incurável!".

Nesta perspectiva, independentemente de quem esteja passando por estágios de sofrimento, se paciente ou cuidador, é necessário "acreditar que Alguém "nos vê" e se importa. Precisamos de um rosto que nos seja familiar e que, de alguma forma, dê sentido a nossa vida e nos lembre quem somos" (OLIVEIRA, 2007, p.29).

Observa-se que há muitas situações vivenciadas pelos profissionais de enfermagem que condizem com a realidade apresentada, particularmente no que diz respeito ao sofrimento do paciente, visto que por muitas vezes o único rosto que vê e que se apresenta na condição de curador são estes profissionais, uma vez que estão com frequência ao lado de quem está exposto à dor, à doença e à morte, onde essas experiências não são mais conceitos abstratos, mas sim realidades comuns.

Portanto, é inegável que o cuidar constitui-se como principal foco da enfermagem, sendo necessário ao enfermeiro amplo domínio de conhecimentos afins, de modo que possa apropriar-se de habilidades e competências condizentes às exigências da profissão em todo o processo de viver, do início ao fim da vida.

Para Moura; Dall'Agnol; Magalhães (2008, p.16),

[...] parte da coordenação do cuidado inclui o compartilhamento de informações sobre as condições dos pacientes e quaisquer modificações que os afetem. Um exemplo geral disso talvez seja a situação em que o enfermeiro investiga um paciente e identifica uma nova limitação funcional. As investigações e as intervenções completas de enfermagem incluem variáveis psicológicas, socioculturais, fisiológicas, de desenvolvimento e espirituais.

Desta forma, torna-se importante destacar que não basta apenas agilizar e organizar o serviço, tampouco estabelecer normas e regras para a continuidade do processo de cuidar, mas, sobretudo, estabelecer uma relação humanizada com os usuários do serviço, buscando a satisfação de suas necessidades básicas baseadas em princípios e condutas de forma acolhedora. 
Nesse sentido, se tem conhecimento de que há algumas décadas passadas iniciou-se um grande movimento sobre o processo de humanização em todo o Brasil, incluindo-se estratégias específicas das mais simples às mais criativas e complexas. Estas por sua vez, encontram-se ainda presentes na atualidade, cuja finalidade tem por fundamento a perspectiva de mudar o modo de gerir a relação entre usuário e profissional da saúde, uma vez que a humanização do atendimento está embasada no desenvolvimento de um trabalho forte com aspectos que valorizem a dimensão humana e subjetiva, presente em todo o ato da assistência à saúde.

Ainda assim, há que se ter consciência de que proceder com processos de humanização implica necessariamente a compreensão do humano em relação ao profissional, ao paciente e aos seus familiares, exigindo dos profissionais de enfermagem e demais atores envolvidos no processo saúde-doença, extrema habilidade, competência e comprometimento com a dimensão sobre o cuidado humanizado.

O processo de humanização, portanto, está diretamente relacionado com a percepção que se tem do ser humano em todas as suas dimensões e manifestações, pois conforme Siedler et al., (2004, p.59), "os laços afetivos tornam as pessoas e as situações preciosas, humanas e portadoras de valores éticos e humanos", como lembra Boff (2013), é o sentimento que nos une às coisas e nos envolve com as pessoas e suscita abertura e acolhimento do diferente. Ainda, de acordo com o autor, "a mão que toca, cura porque leva carícia, devolve confiança, oferece acolhida e manifesta cuidado. A mão faz nascer a essência humana naqueles que são tocados" (BOFF, 2013, p.198).

É importante que se possibilite a criação de um clima e vínculo afetivo e de confiança neste entorno, observações que se aplicam tanto para as dificuldades cotidianas quanto para situações mais dramáticas, como acontece com a maioria dos indivíduos acometidos pela enfermidade.

Nesse sentido, é importante destacar que saber ouvir, mesmo quando a escuta se apresenta de forma silenciosa, facilita a compreensão do diálogo se o profissional se mostrar 'aberto' ao paciente, gerando assim reações entre os seres humanos em questão, provocando, desta forma, "reflexões acerca de questões axiomáticas como a convivência, a tolerância, o respeito, a hospitalidade, a ecologia, a espiritualidade do ser humano" (BARRA, 2010, p.204).

Nesta perspectiva, destaca-se que o cuidado dispensado aos enfermos é cultural e varia de acordo com o transcorrer da história. Em um período mais primitivo, a doença era tida como mácula divina, onde o portador tinha que ser deixado ao abandono. Com a saúde mais 
humanizada e a interferência atuante dos cristãos, o doente passa a ser estimado como um ser humano frágil e com necessidades protetivas.

Almeida e Pires Junior (2013, p.207) ilustram o contexto ao destacarem que cuidar é amar de forma desinteressada, pois "o cuidado de si, que se forma e só pode formar-se numa referência ao outro", ou seja, "é preciso edificar-se a si mesmo para ser capaz de cuidar de si e consequentemente cuidar do outro, o diálogo entre edificação e cuidado é pertinente e necessário".

Destaca-se, portanto, que a humanização está diretamente relacionada com a capacidade de saber ouvir, dialogar e, sobretudo amar, haja vista que estes preceitos por natureza são contagiantes, interferindo sobremaneira na possibilidade de amenizar um sofrimento, principalmente quando se está em um ambiente estruturado e ao lado de pessoas capazes de entender a 'humanização' como qualidade de vida necessária para o bem-estar de todos.

O contexto reporta à hospitalidade, que é definida sempre a partir do outro, pois segundo Boff (2005, p.96), é reconhecida como intimamente ligada aos cuidados humanos: "ser acolhido sem reservas, poder abrigar-se, comer, beber e descansar", que por sua vez é revelada nas ações de enfermagem, onde o acolher generoso, o escutar com atenção e o diálogo franco fazem parte de um ser sensível e frágil, porém um ser repleto de esperança com inúmeras capacidades motivacionais e positivas.

Nessa perspectiva, é pertinente elucidar que o enfermeiro deve proceder com ações que se voltem para a atenção com pessoas enfermas, não somente no que diz respeito à assistência, mas, sobretudo, educativa e humanizada, fundamentadas em aspectos amorosos e cordiais, onde a análise das causas das doenças não seja embasada somente no organismo enfermo, mas também e principalmente no que se diz respeito à essência humana: o espírito, peça chave que diferencia o ser homem de outros tipos de organismos com vida no planeta Terra.

Desta forma, destaca-se que a valorização das necessidades tanto físicas quanto subjetivas e respeito ao paciente torna o serviço mais humanizado, mesmo entendendo que o termo humanização é amplo e complexo, haja vista que apresenta-se como algo difícil de lidar em função de se tratar da condição de humanizar o humano.

A qualidade do cuidado assim como as ações de tratamento e de serviços disponibilizadas pelos enfermeiros afeta consideravelmente a recuperação ou não de pacientes, haja vista a frequência com que profissional e paciente se relacionam cotidianamente, pois é 
com estes indivíduos que o profissional passa grande parte de seu tempo; uma reciprocidade que estimula a qualidade do cuidado e contribui para promover ações humanizadoras.

Nesse sentido, torna-se relevante destacar que a espiritualidade é um fator importante e merece atenção no exercício dos profissionais de saúde, visto que a sensibilização e compreensão por parte do enfermeiro ao olhar o sofrimento alheio remete à compaixão amável, humanizada, essencial ao trabalho do ser humano que cuida de outro ser humano, tendo como ponto de partida a alteridade ${ }^{2}$ (DUARTE, 2002).

De acordo com Farah e Sá (2008, p.147), “não há como cuidar da espiritualidade do outro se a do profissional não estiver desenvolvida". Assim com a elevação da espiritualidade, os profissionais de saúde desenvolvem maior capacidade de visualizar outras possibilidades de cuidado e menor capacidade à concretização e coisificação das pessoas que estão sob sua responsabilidade, ultrapassando o material/físico, para assim almejar outros parâmetros que possam tocar internamente o centro da essência humana perfeitamente identificada em seus pacientes fragilizados, mas ainda humanos.

Desta forma, para melhor compreensão do estudo, será abordada a seguir, a contextualização analítica dos 'cuidados paliativos' como qualidade de vida e a respectiva relação enfermeiro-paciente oncológico na dor e sofrimento, assim como a inserção da importância da espiritualidade e religiosidade para a melhoria do quadro clínico do paciente.

\section{Visão Humanística dos Cuidados Paliativos: Relação Enfermeiro-Paciente Oncológico}

Eu me importo pelo fato de você ser você, me importo até o último momento de sua vida e faremos tudo o que estiver a nosso alcance, não somente para ajudá-lo a morrer em paz, mas também para você viver até a dia da morte.

Cicely Saunders

Percebe-se nas palavras de Cicely Saunders o âmago que resume o significado filosófico dos cuidados paliativos. Saunders (1980) introduziu este modelo de cuidados em 1984, quando se iniciou o processo da medicina paliativa no cuidado e não na cura definitiva do paciente. Essa filosofia associada ao trabalho da equipe de saúde multidisciplinar, incluindo-se o controle

\footnotetext{
${ }^{2}$ Em ser e tempo, a questão do outro e da alteridade é entrevista a partir de um duplo deslocamento teórico: em primeiro lugar, o problema do encontro e do reconhecimento do outro no mundo deixa de ser pensado por meio do recurso à atividade especulativa do sujeito isolado, ou ainda, por meio da empatia analógica, que transforma o outro em um duplo de mim mesmo. 
de dor e o alívio de sintomas, procura compreender o paciente, a família e a comunidade, cuja finalidade tem por fundamento reduzir o sofrimento e oferecer cuidado total.

Como se observa, esta filosofia vai além de aspectos sobre cuidados, ou seja, propõe perspectivas de proceder com suporte individual e familiar para indivíduos que estão vivendo com doenças crônico-terminais em fase avançada. Nesta perspectiva, em 1980 a Organização Mundial de Saúde (OMS) introduziu o conceito de Cuidados Paliativos como ações estratégicas específicas, cuja finalidade é possibilitar o aumento da qualidade de vida, não somente de pacientes, mas também, incluem-se neste contexto, familiares que enfrentam uma doença terminal, e que se efetivam através da prevenção e alívio do sofrimento a partir da identificação precoce, avaliação correta e tratamento da dor e outros problemas físicos, psicológicos, sociais e espirituais.

Nesse sentido, salienta-se que a sintomatologia é de suma importância no contexto que envolve os cuidados paliativos, contudo não se resume somente a isso, uma vez que ao se referir a 'cuidados paliativos', importa dizer que estes são mais profundos e alcançam amplitudes holísticas, onde a dimensão física se faz presente e deve ser relacionada com outras dimensões, incluindo-se as psicológicas, sociais e espirituais, oferecendo assim novas possibilidades de opção de tratamento ou de simplesmente estar ali e proceder com a escuta ativa do paciente.

De acordo com Maciel (2008, p.17),

[...] na fase final da vida, entendida como aquela em que o processo de morte se desencadeia de forma irreversível e o prognóstico de vida pode ser definido em dias a semanas, os Cuidados Paliativos se tornam imprescindíveis e complexos o suficiente para demandar uma atenção específica e contínua ao doente e à sua família, prevenindo uma morte caótica e com grande sofrimento. A prevenção continua sendo uma demanda importante neste período. Ações coordenadas e bem desenvolvidas de cuidados paliativos ao longo de todo o processo, do adoecer ao morrer, são capazes de reduzir drasticamente a necessidade de intervenções, como uma sedação terminal ou sedação paliativa.

Interessante salientar que, com a sedação terminal, perde-se totalmente o contato entre família-paciente e enfermeiro-paciente. Necessário é valorizar nessa fase da vida terminal do ser adoecido a dignidade de escolher a melhor forma de morrer. Tal valorização vem através de um termo de consentimento livre e informado, onde, o mesmo, poderá demonstrar seu desejo declarado em documento sobre a melhor forma de viver e de morrer com dignidade. Na falta do documento, faz-se necessário avaliar a opinião de familiares mais próximos do paciente, levando em consideração as condições socioeconômicas da família no que diz respeito a manutenção do cuidado. 
O profissional não deve emitir opinião sobre a escolha, porém deve se esclarecer as possibilidades mais viáveis no momento.

Farah e Sá citam em seu livro os objetivos do tratamento de pacientes terminais. Entre esses destacam-se: conscientizá-lo da fase final da doença, disponibilizar o máximo possível de conforto, conservar a dignidade do paciente e preparar a todos, cuidadores e familiares para saber lidar com essa fase da doença, não antecipar, nem estender a morte.

Observa-se, portanto, que a filosofia estabelecida pelos cuidados paliativos, no tocante à dor e sofrimento de seres humanos sem possibilidade de cura, ou mesmo na condição humana adoecida surge como esperança para se obter um cuidado digno.

Dreher (2007, p.179) ilustra com precisão as palavras de Küber-Ross (2000), quando refere que "a morte pertence à vida, como pertence o nascimento. $\mathrm{O}$ caminhar tanto está em levantar o pé como em pousá-lo”. Conviver com essas pessoas é também conviver com o findar de sua vida. Saber a hora de pousar o pé, de aceitar a morte e acompanhar essas pessoas no seu processo de morte requer sabedoria, fé e aquilo que nos é intrínseco, humanidade.

Nesta perspectiva, é imprescindível destacar que os enfermeiros necessitam adquirir conhecimentos e habilidades suficientes para cuidar de seus pacientes que apresentam sintomas agressivos e estão em fase terminal. Nesse sentido, algumas diretrizes e programas específicos foram normatizados, de modo que se possa atender as necessidades desses pacientes sem possibilidade terapêutica de cura.

De acordo com Maciel (2008, p.17),

[...] na fase avançada de uma doença e com poucas chances de cura, os sintomas físicos são fatores de desconforto. Para estes existem procedimentos, medicamentos e abordagens capazes de proporcionar um bem-estar físico até o final da vida. Esta terapêutica não pode ser negada ao doente. O caminho da informação adequada, da formação de equipes profissionais competentes, da reafirmação dos princípios dos Cuidados Paliativos e da demonstração de resultados positivos desta modalidade de tratamento, constitui em a melhor forma de transpor barreiras ainda existentes para a implantação de uma política de Cuidados Paliativos efetiva e integrante de todas as políticas públicas de saúde.

Portanto, é de suma importância proceder com a possibilidade de oferta de Cuidados Paliativos em enfermagem e, sobretudo, compartilhar momentos de amor e compaixão, assim como se apropriando de reflexões sobre a possibilidade de aprender que é possível morrer com dignidade e graça; proporcionar ao paciente a certeza de que estes não estão na condição de solidão no momento da morte, muito pelo contrário, deve-se propor ensinamentos onde o foco esteja fundamentado em parâmetros sobre uma morte tranquila e digna com cuidado holístico. 
Desta forma, fica evidente a necessidade de se proceder com uma abordagem especializada como meio estratégico de auxílio aos indivíduos em sua vivência e, principalmente o encarar a morte da melhor forma possível, onde a espiritualidade possa se fazer presente para compreensão sobre questões finais da vida e sua relação com o sagrado e o transcendente. Assim, acredita-se na possibilidade de minimizar o sofrimento diante dessas dificuldades ou mesmo para simplesmente poder obter maior esperança de cura através de algumas terapêuticas, configurando-se como importante caminho para que os indivíduos que se encontram nesta situação possam lidar com a terminalidade.

Nesse sentido, é relevante reportar às palavras de Evangelista et al., (2016, p.596), quando referem que,

[...] a espiritualidade é um conceito multidimensional que compreende a busca de significados para a vida e a transcendência. Pode estar relacionada com a fé em Deus ou em uma força superior. É uma característica inata do ser humano e refere-se à busca por um sentido transcendente de vida, que pode acontecer pela religião, arte, música, natureza e solidariedade. Trata-se de um componente que auxilia os indivíduos a descobrir seu verdadeiro potencial, a ter mais confiança em si mesmo e coragem para amar e perdoar, e permite que transcendam o sofrimento.

Nesta perspectiva, embora se tenha conhecimento da necessidade de os profissionais de saúde prestar um cuidado competente, qualificado e diferenciado ao fim da vida, cada qual com sua formação, ainda assim, é preciso que estes profissionais tenham potencial suficiente para otimizar cuidados de natureza não apenas física, prevenindo assim, complicações indesejáveis.

Desse modo, observa-se que os cuidados de enfermagem não devem ser prestados somente quando a pessoa se encontra doente, mas também em situação de saúde. Eles estão além do estado de doença, mesmo em situações quando não há mais nada a fazer em questões relacionadas às medidas curativas, pois ainda assim, a possibilidade de cuidar é real.

Nos últimos anos se tornou possível analisar estas situações, assim como buscar entendimento de que não existe a incapacidade de se fazer alguma coisa, ao contrário, tem-se muito que fazer. Assim, entre estas opções, busca-se apoio nas ações sobre os cuidados paliativos, onde os planos possam estar embasados nas mais variadas formas, como referido anteriormente: clínica, psicológica, espiritual e social. Desta forma, deve-se promover cuidados especiais de conforto global, uma vez que ao se fazer referência ao termo doença terminal, se está referindo a reduzido espaço de tempo para a intervenção do profissional da saúde para com o paciente sem perspectiva de tempo de vida. Isto é, nos cuidados paliativos não há mais 
expectativas de se propor ações sobre a causa e sim trabalhar incansavelmente para amenização do sofrimento, dor e controle de feridas.

De acordo com Silva; Araújo; Firmino (2008, p.62),

[...] por meio da compreensão da natureza humana, sua atenção é direcionada para as necessidades holísticas do paciente. Cabe ao profissional identificar e compreender as demandas e os desejos individuais de cada ser cuidado, planejando e implementando ações que permitam ao indivíduo o máximo controle sobre sua própria vida e doença. Preservar a autonomia do paciente, exercitando sua capacidade de se autocuidar, reforçando o valor e a importância da participação ativa do doente e seus familiares nas decisões e cuidados ao fim da vida, permitindo uma melhor vivência do processo de morrer. Quem faz Cuidados Paliativos tem um desafio a mais: ser maleável, entender que é desejável atender às necessidades do paciente em detrimento, às vezes, de algumas normas e protocolos de serviço e até... de algumas vaidades pessoais.

Nesse contexto, fica evidente destacar que a perda de tempo com medidas curativas deve ser evitada, direcionando o enfermeiro a fomentar o entendimento do paciente sobre o processo de cuidar e a importância da participação ativa do mesmo, pois com isso haverá possibilidades de mudanças de atitudes consideráveis diante do cuidado (cuidando que se promove autoconsciência e autocuidado). Diante disso, entende-se que nesta relação cuidador-paciente existe expectativas de se estabelecer uma troca sensível de aprendizagem, onde cada encontro se transforme em uma simples oportunidade de se estar com o outro para apreender e direcionar a prática da observação, uma relação de cumplicidade que permita efetivar a tão sonhada humanização, pois a partir daí com certeza será possível melhorar a relação juntamente com as ações desenvolvidas na práxis profissional.

Para Santos (2009, p.90), o outro é um "ser único, construtor de uma história que, assim como a nossa, terá um desfecho e a dignidade será atingida quando o auxiliarmos a assinar, com dignidade, a última página do livro da vida”, e deve, portanto, ser respeitado na íntegra, ou seja, concedendo-lhe oportunidade para escolhas e direcionamento da sua vida com dignidade e autonomia.

Por fim, quando as ações de conforto estão direcionadas à busca de alívio e sofrimento humano diante da morte, torna-se evidente expandir a compreensão do ser humano para além de sua dimensão biológica, uma vez que entende-se que a grande síntese da espiritualidade no fim da vida está diretamente vinculada à reconciliação com tudo e todos.

Entretanto, se tem conhecimento de que entre as principais dificuldades para se proceder com a abordagem sobre questões espirituais no final da vida está, entre outras situações, o próprio desconhecimento da equipe de saúde a respeito da sua espiritualidade e, ainda, a 
ignorância do paciente em relação à sua finitude, o que acaba por impactar sobremaneira estes parâmetros, uma vez que a morte é a última crise, não a ser enfrentada, mas aceita como um processo natural da vida, a mesma também é tida como uma oportunidade para o crescimento espiritual, sendo seu grande desafio o de manter íntegra a identidade da pessoa diante da desintegração total.

Saporetti (2008, p.528) contribui para que este desfecho possa ter êxito em seu contexto reflexivo, pois o conhecimento das diferentes tradições espirituais, assim como a clareza com relação às suas próprias questões espirituais auxiliará muito no cuidado do paciente nessa fase da vida. Portanto, não é impossível auxiliar alguém em suas questões espirituais sem antes conhecer a sua própria espiritualidade. Diante do exposto, faz-se necessário que a equipe esteja disposta a trabalhar com as crenças e a fé do paciente sem, em nenhum momento, pregar a sua verdade. Desta forma, os cuidadores deverão ser orientados com relação ao respeito à individualidade do paciente, sendo que o cuidado espiritual cabe a todos os envolvidos, todavia, a assistência religiosa, com seus ritos e sacramentos, deve ser incentivada pela equipe e ministrada pelo sacerdote habilitado.

\section{Considerações Finais}

Humanizar incita reflexões paradoxais do adjetivo humano que contrapõe o adjetivo desumano. O estudo, guiado sob a luz da proposta da pesquisa (objetivo geral), fez-se necessário para alcançar um bom resultado, delimitar atividades investigadoras para uma dimensão específica do cuidado paliativo na análise holística do ser humano (bio-psico-socialespiritual).

Quando o ser humano consegue enxergar o seu semelhante em sua totalidade, o cuidado se torna mais completo e humanizado. Porém, o olhar do agente enfermeiro para o paciente deve ser individual e, preferencialmente, específico, pois cada ser humano constitui-se como um ser único, dotado de particularidades próprias.

O ser humano pode sofrer com seus conflitos em níveis diferentes, isso vai depender de como é encarado o problema que decorre da experiência de vida, onde, uns são mais fortes que outros. Isso significa dizer, que no sofrimento da doença, a análise da totalidade é importante, porém deve-se considerar a subjetividade do paciente, pois os humanos se diferem uns dos 
outros, isso faz com os cuidados sejam dispensados de acordo com a especificidade do enfermo para que possamos chegar ao ser total de cada um.

O enfermeiro deve olhar para os seus pacientes de maneira holística e empática, utilizando-se de alteridade no processo de saber/fazer saúde em oncologia para pacientes que têm de enfrentar a dura realidade do fim da vida.

A fragilidade humana, neste contexto, representa um grande desafio para os profissionais enfermeiros que lidam diretamente com pacientes oncológicos sem possibilidade terapêutica de cura. Entretanto, esses profissionais devem ser treinados de forma que possam prestar uma assistência humanizada, que permitam ao paciente demonstrar sua autonomia e dignidade para que haja uma melhor qualidade de vida.

Isto só será possível com a implementação da filosofia dos Cuidados Paliativos, onde o enfermeiro deve favorecer o acolhimento continuado, tanto transmitindo informações objetivas, como ofertando uma escuta ativa que possibilite o reconhecimento da demanda subjetiva e singular do usuário durante todo o processo de atenção à saúde. Por isso, a enfermagem é considerada a arte do cuidar.

Às vezes, não basta somente conhecer as técnicas de enfermagem sobre cuidados paliativos de pacientes à beira da morte; é preciso ir além das técnicas.

A dor e o sofrimento podem ser físicos como também espirituais, e a cura pode ser possível. Entretanto, diante da incurabilidade não se pode insistir em tratamentos fúteis e desnecessários. Há possibilidade de ser técnico e não deixar de ser humano, onde muitas vezes pode-se expressar através da fala, estando ciente de que nem sempre as palavras vão resolver a situação e, neste caso, é preferível o toque das mãos, pois a medicação alivia a dor e a meditação fortalece o espírito.

Quando tudo parece perdido e as lágrimas são inevitáveis, as palavras não confortam, pois escapam de nossas mentes por falta de segurança frente à finitude humana. É aí que se faz necessário utilizar o toque das mãos. Esse simples gesto pode revelar amor e até curar a alma dos pacientes que apresentam um câncer agressivo e estão desesperançados, pois, onde as palavras não conseguem alcançar, quando nos sentimos fragilizados diante dos cuidados paliativos de pacientes no fim da vida, a mão representa uma ferramenta poderosa para quem a sabe usar. Nesse contexto, deve-se buscar informações relevantes, mesmo que de outras áreas de atuação para ajudar no tratamento do paciente, fortalecendo assim, o vínculo entre as partes. 
O olhar para o eu interior do outro, revela suas necessidades mais impactantes a serem captadas nos momentos de dor e sofrimento. Para poder entendê-lo e assim apreender em sua dignidade plena nas dimensões bio-psico-socio-espiritual, o enfermeiro deve usar de alteridade. O olhar holístico permite ao enfermeiro enxergar além do que os olhos podem ver. A alma do paciente se revela em sua essência humana como componente de sua espiritualidade que o faz diferente dos outros seres viventes do planeta.

A esperança trazida pela fé o alimenta no sentido de que a vida após a morte não será efêmera, e sim, eterna, sem dor e sem sofrimento, onde todas as suas lágrimas serão enxugadas e o que era, não será mais.

\section{Referências}

ALMEIDA, J.M.; PIRES JR, H. Subjetividade da subjetividade: a propósito da relação entre Kierkegaard e Foucault. Anais da XIII Jornada Internacional de Estudos de Kierkegaard da SOBRESKI - Sociedade Brasileira de Estudos de Kierkegaard. Vitória da Conquista, 2013.

BARRA, D.C.C. et al. Hospitalidade como expressão do cuidado em enfermagem. Rev. Bras. Enferm., Brasília, mar-abr.; 63(2):203-8, 2010.

BOFF, L. Virtudes para um outro mundo possível - Hospitalidade: direito e dever de todos. Petrópolis: Vozes; 2005.

Saber cuidar: ética do humano - compaixão pela terra. 19. ed. Petrópolis: Vozes, 2013.

DREHER, S.C. Musicoterapia e oncologia. In: Sofrimento, resiliência e fé. Organizado por HOCH, L.C. e ROCCA, S.M. São Leopoldo: Sinodal/EST, 2007.

DUARTE, A. Heidegger e o outro: a questão da alteridade em ser e tempo. Departamento de Filosofia da Universidade Federal do Paraná - UFPR. Natureza Humana 4(1):157-185, janjun. 2002.

EVANGELISTA CB, LOPES MEL, COSTA SFG, BATISTA PSS, BATISTA JBV, OLIVEIRA AMM. Palliative care and spirituality: an integrative literature review. Rev Bras Enferm [Internet]. 2016;69(3):554-63.

FARAH, O.G.D.; SÁ, A.C. (Orgs.). Psicologia aplicada à enfermagem. Barueri: Manole, 2008. 
MACIEL, M.G.S. Cuidados Paliativos: definições e princípios. Coordenação Institucional de Reinaldo Ayer de Oliveira. São Paulo: Conselho Regional de Medicina do Estado de São Paulo, 2008. 689 p.

MOURA, G.M.S.S.; DALL'AGNOL, C.M.; MAGALHÃES, A.M.M. Temas e estratégias para liderança em enfermagem: enfrentando os desafios hospitalares atuais. Joint Commission Resources. Trad. Ana Thorell. Porto Alegre, 2008.

OLIVEIRA, R.M.K. Implicações para as relações de cuidado.In: Sofrimento, resiliência e fé. Organizado por HOCH, L.C. e ROCCA, S.M. São Leopoldo: Sinodal/EST, 2007.

SANTOS, F.S. Cuidados Paliativos: discutindo a vida, a morte e o morrer. São Paulo: Editora Atheneu, 2009.

SAPORETTI, L.A. Espiritualidade em cuidados paliativos. Coordenação Institucional de Reinaldo Ayer de Oliveira. São Paulo: Conselho Regional de Medicina do Estado de São Paulo, 2008.

SAUNDERS, C.M. La filosofia del cuidado terminal. In: Saunders CM. Cuidados de la enfermedad maligna terminal. Argentina: Salvat, 1980.

SIEDLER, A.J. et al. O. Humanização em ação: sensibilizando os profissionais para o processo de humanização. In: Boletim da Saúde. Porto Alegre. vol.18. n.2. Jul/dez, 2004.

SILVA, M.J. P.; ARAÚJO, M.T.; FIRMINO, F. Cuidados Paliativos: Enfermagem. Coordenação Institucional de Reinaldo Ayer de Oliveira. São Paulo: Conselho Regional de Medicina do Estado de São Paulo, 2008.

\section{Como citar este artigo (Formato ABNT):}

SANTOS, Elenito B. O Papel do/a Enfermeiro/a: Visão Humanística dos Cuidados Paliativos em Pacientes Oncológicos. Id on Line Revista ultidisciplinar e de Psicologia, 2017, vol.12, n.39, p.396409. ISSN: 1981-1179.

Recebido: 15.12 .2017

Aceito: 18.12.2017 